\title{
A Forecasting Model for Satisfying the Demand of International Flight Passengers Having Domestic Flight Connection
}

\author{
Riyadh Alhassan, Reda Abdulaal and Hemaid Alsulami \\ Industrial Engineering Department, Faculty of Engineering, King Abdulaziz University \\ Jeddah, Saudi Arabia \\ engr.riyadhali@gmail.com
}

\begin{abstract}
This paper deals with one of the main problems, which is faced by Saudi Arabian Airlines (SAUDIA). The problem of the passengers who have international flights and cannot able to find their seats easily on their domestic flights to have a smooth connection to their international flights. As a result, those passengers are left with no choice except to look for any alternative Airlines, making the demand on domestic flights of Saudi Arabian Airlines diminish and increase the revenue of its competitors. The paper focused on the problem of passengers who look for seats on domestic flights between Abha and Riyadh to continue their international flights. The data collected for the demand on fourteen international destinations, which have a connection between Abha and Riyadh, emphasizing on the analysis of the three top international destinations, which are in high demand. Using descriptive statistics, ARIMA (box and Jenkins) procedure and multiple regressions, a forecasting model was developed to determine the expected demand on the domestic flights under study. Recommendations were made to SAUDIA operational strategy (i.e., the types of aircrafts and their capacity) to fulfill the demand in order to maximize the total revenue of Saudi Arabian Airlines in comparison with its competitors.
\end{abstract}

Keywords: Air travel demand analysis, Network and scheduling planning, Airlines operational strategy, Descriptive statistics tools, Box-Jenkins forecasting, Time series forecasting.

\section{Introduction}

The Saudi Arabian Airlines, commonly known as SAUDIA (SV), was officially established in the year 1945, a year after the Kingdom's skyline witnessed the first flight of a DC-3 aircraft gifted to King Abdul-Aziz bin AbdulRahman Al-Saud by the US President Franklin D. Roosevelt ${ }^{[1]}$. SAUDIA is one of the major carriers in the Middle East, operating flights to around 80 domestic and international destinations. The number increased to more than 100 destinations during Hajj and Umrah seasons, when pilgrims from different parts of the world visit holy places in the Kingdom [1]. The Network and Revenue management carries out all fleet and schedule planning keeping in view the demand-forecast to accommodate passengers. These days, SAUDIA operates a fleet of 122 jets to various destinations, viz., Middle East, Africa, Indian subcontinent, Far East, Europe, and the United States, to increase its revenue. SAUDIA has played an important role in the Kingdom's social, cultural and economic development as it carries an average of over 27 million passengers each year. Entry of foreign airlines to the strategic depth of SAUDIA network with a low flight cost and high capacity aircrafts made those direct competitors on both domestic and international flights became the clear effect and a decline in the number of passengers traveling through SAUDIA network, which lead SAUDIA to face one of the problems of revenue. The purpose of this paper is to find an operational strategy that can 
resolve the passengers' problem that has connections to their international flights, but they cannot find seats easily on their SAUDIA domestic flights. As a result of which, they opt for any alternative airlines in order to have connections to their international flights easily, giving way for a decline in the revenue of the National carrier. Operational strategy means, finding the type of aircraft and its capacity, which can fulfill the passengers' demand.

The next section demonstrates the models commonly applied for forecasting airline's passengers demand followed by analysis of the proposed forecasting methodology and finally presenting the recommendations of operational strategy.

\section{Literature Review}

Unquestionably, analyzing and forecasting air travel market is a part of the planning process for any airlines. The statistical analysis showed a strong relationship between the air travel demand and the economic activity in the Kingdom of Saudi Arabia. This paper addresses the decisive factors of domestic air travel demand in the Kingdom. An attempt is made to develop a model for forecasting domestic air travel demand with different combinations of explanatory variables utilizing stepwise regression technique. There are several different methods, ranging from time series techniques to econometric models, for analyzing and forecasting the air travel market [2-6]. The time series approach is the most common methods for forecasting the traffic demand. It assumes that the traffic demand has behaved in accordance with a specific pattern in the past and in the future, this pattern will continue to be dominated ${ }^{[2]}$.

There is a large amount of literature regarding air passenger's forecasting with time series techniques. Most of the published studies tend to concentrate on three specific regions:
The United States, Europe and the Asia Pacific region ${ }^{[7-10]}$. These literatures provide monthly forecasts of enplaned/deplaned of air passengers for three market segments (domestic, international and trans-border flights). Various time series models were suggested and applied accordingly, namely, Seasonal AutoregressiveIntegrated-Moving Average model (SARIMA), Structural Time Series model (STSM), Seasonal Unit Roots model (SUR), and simple average combination method [11, 12]. In general, the forecasting performance depends on two key elements: The Market Segment and the Forecasting Horizon, for example, short and long-time series models were applied to forecast seasonally unadjusted monthly data of Canadian enplaned/deplaned air passengers, for the domestic, trans-border and international sectors. The forecasting performance of the models varies widely across series and forecast horizons. It uses various time series forecasting models: harmonic regression, Holt-Winters exponential smoothing, autoregressiveintegrated-moving average (ARIMA) and seasonal autoregressive-integrated-moving average (SARIMA) regressions the forecasting results while comparing with forecasts published by Transport Canada's Aviation Forecasting Division, it was clear, that the short memory models are better for short term forecasting whereas long memory models are better for long term forecasting ${ }^{[13]}$.

On the other hand, AutoregressiveIntegrated-Moving Average (ARIMA) and SARIMA models are among the most widely used in the air passenger forecasting demand. Their popularity comes from the fact that they are based on very few assumptions besides they are easy to specify with the recursive BoxJenkins methodology ${ }^{[14,15]}$. Many studies have examined the performance of ARIMA and SARIMA models for predicting air traffic flows. For example, forecasts of air travel from the United Kingdom to twenty destinations using 
quarterly data of UK outbound air travelers with several models, which include the Naive 1 model, the Naive 2 model, the Holt-Winters model and a variety of ARIMA models. From the Root Mean Squared Error (RMSE) point of view, ARIMA model outperforms the other models ${ }^{[16]}$. The preceding studies suggest that the forecasting performance of ARIMA and SARIMA models varies with the market segment, which consider, the forecasting horizon as well as the origin and destination countries of the passengers. In addition, these two models, generally, found to offer accurate forecasts in the short and medium term.

\section{The Proposed Forecasting Methodology}

The proposed methodology is based on two successive stages in which the first stage exhibits the descriptive statistics while the second stage exhibits the time series forecasting analysis. The methodology started with data collection followed by data analysis and ended by results ready for application at Saudi Arabian Airlines.

\subsection{Data Collection}

As mentioned before, this paper aims to tackle the problem of the passengers who have international flights via connecting domestic flights between Abha (AHB) and Riyadh (RUH). These domestic flights contained high demand of connecting passengers from RUH station to the following 14 international flights:

1. Indian subcontinent region: "Dhaka (DAC) and Islamabad (ISB)".

2. Asia Pacific region: "Manila (MNL) and Jakarta (CGK)". (DOH)".

3. Gulf region: "Dubai (DXB) and Doha

4. Africa region: "Addis Ababa (ADD) and Alexandria (HBE)".
5. Europe region: "Istanbul (IST) and London (LHR)".

6. Middle East region "Amman (AMM) and Beirut (BEY)" .

7. America region "Washington (JFK) and New York (IAD)".

The Network and Revenue Management Department, at Saudi Arabian Airlines, in the period from January 2014 to the end of October 2016, recorded 36456 connecting passengers via 15632 demands over the 14 international destinations. Table 1 shows the number of times (frequent time) each destination was requested by connecting passengers during the weekdays. In this paper, the analysis applied to the three top demanded connections, which are from AHB-RUH to DAC, AHB-RUH to ISB, and AHB-RUH to MNL.

\subsection{Data Analysis}

The collected data analyzed by three descriptive statistics techniques (descriptive tables, statistical measurement, and cross tabulation) followed by two methods of time series forecasting (multiple regression modeling and ARIMA modeling). The importance of descriptive statistics is to analyze the data of 14 international destinations in a manner that helps describing the significance of each data variable independently besides summarize the data in a meaningful way. On the other hand, the time series methods identify the patterns in correlated data besides prediction the trends to build the future operational strategy at Saudi Arabian Airlines.

\subsubsection{Data Analysis by Descriptive Statistics Techniques}

The data variables treated as (1) Categorical ordinal variables and (2) Numeric continuous variables to find the demand behavior of the connecting passengers at Saudi 
Arabian Airlines. The first treatment, as categorical data variables, applied to answer the following questions:

- What are the most preferred days of the week for connecting passengers?
- What are the most frequent domestic flights from AHB station to RUH station?

- What are the most frequent flights from RUH to international destinations?

- What are the most preferred months of the year for connecting passengers?

Table 1. Cross tab for demanded flights in the period from 1 January 2014 to 31 October 2106.

\begin{tabular}{|c|c|c|c|c|c|c|c|c|c|c|c|c|c|c|c|}
\hline \multirow{2}{*}{ Weekdays } & \multicolumn{14}{|c|}{ Frequent Times from Riyadh (RUH) to 14 international destinations over weekdays } & \multirow{2}{*}{ Total } \\
\hline & ADD & AMM & BEY & CGK & DAC & DOH & DXB & HBE & IAD & ISB & IST & JFK & LHR & MNL & \\
\hline Sun. & 359 & 194 & 56 & 307 & 124 & 69 & 160 & 39 & 38 & 209 & 137 & 15 & 6 & 451 & 2164 \\
\hline Mon. & 120 & 183 & 55 & 0 & 366 & 87 & 176 & 8 & 38 & 137 & 161 & 44 & 59 & 502 & 1936 \\
\hline Tue. & 392 & 160 & 68 & 321 & 374 & 89 & 181 & 90 & 46 & 261 & 165 & 11 & 62 & 497 & 2717 \\
\hline Wed. & 84 & 214 & 35 & 267 & 231 & 71 & 148 & 41 & 70 & 392 & 140 & 4 & 61 & 32 & 1790 \\
\hline Thu. & 325 & 189 & 68 & 177 & 590 & 104 & 154 & 109 & 23 & 362 & 162 & 48 & 96 & 467 & 2874 \\
\hline Fri & 124 & 283 & 59 & 4 & 354 & 112 & 209 & 4 & 53 & 327 & 134 & 22 & 18 & 557 & 2260 \\
\hline Sat. & 53 & 161 & 66 & 83 & 310 & 94 & 185 & 64 & 59 & 64 & 143 & 42 & 131 & 436 & 1891 \\
\hline Total & 1457 & 1384 & 407 & 1159 & 2349 & 626 & 1213 & 355 & 327 & 1752 & 1042 & 186 & 433 & 2942 & 1563 \\
\hline
\end{tabular}

The second treatment, as continuous data variables, applied to find the mean, the mode, the median, the standard deviation, the range, and the shape of data distribution (skewness) for the data set related to each question of the above four.

Several factors affecting the connecting passengers' demands such as stability of departure time in both domestic and international flights, availability of domestic flight that can easily connect with international flights, suitability of ticket prices, elapse time for connecting passengers between domestic and international flights, weekdays and months promotions, availability of desirable seats in domestic flights, and seasonality passengers holidays.

\subsubsection{Data Analysis by Multiple Regression and ARIMA Forecasting Techniques}

Multiple regression used to assess the relationship between a dependent (predicted) variable and several independent (predictor) variables. Here, the dependent variable is the numbers of connecting passengers while the independent variables are the connection time, inbound flights, days of the week, and months of the year. The end-result of multiple regression is the development of a regression equation (line of best fit) between the dependent variable and independent variables.

ARIMA used to predict the number of passengers willing to connect from domestic flights AHB-RUH to top three demanded international destinations, which are DAC, ISB, and MNL. For each destination, the data for inbound/outbound flights, inbound/ outbound legs, flights loading factor (LF), connections time, connecting passengers, days of the week (DOW), and month of the year are taking into ARIMA considerations. Table 2 shows sample of the data related to the connecting passengers from AHB to DAC.

\section{Results and Discussions}

\subsection{The Results Obtained from Descriptive Statistics Techniques}

- Thursdays and Tuesdays are the most frequent days of the week that have connecting passengers with percentages $18.4 \%$ and $17.4 \%$ respectively. 
- The flights SV1672, SV1620, SV1654, SV1696, and SV1622 are the most frequent flights from AHB to RUH that have connecting passengers with percentages $10.6 \%, \quad 10.0 \%, \quad 9.6 \%, \quad 9.2 \%$, and $8.9 \%$ respectively.

- The most frequent outbound legs are RUH-MNL, followed by RUH-DAC, and then RUH-ISB with percentages $18.8 \%, 15.0 \%$, and $11.2 \%$ respectively.

- January and May are the most frequent months of the year that have connecting passengers with a percentage of $9.6 \%$ each.

- The mean loading factor is $93.2 \%$ for all 15635 domestic flights from AHB to RUH that contain connecting passengers to international flights. The maximum and minimum loading factors are $100 \%$ and $4 \%$ respectively. The value of standard deviation that presents data distribution is $12.4 \%$.

- The mean connecting passengers for all domestic flights is about four passengers while the mode is only one passenger. This indicates that, the most of the flights were booked for domestic passengers and was difficult to find a seat for connecting passengers. As a result, the connecting passengers go to the competitive airlines.

- The mean connection time for all flights is about 5 hours while the mode is only 1:30 hours. The value of standard deviation is about $3: 45$ hours and the minimum connection time is only one hour which is in contradict to the maximum connection time which is 24 hours.

The following results are also obtained for the top three demanded international destinations:
- Inbound flights SV1620 and SV1672 have the most demand to connect passengers from AHB to DAC destination with 622 and 480 frequent times respectively (Fig. 1).

- Inbound flights SV1620 and SV1678 have the most demand to connect passengers from AHB to ISB destination with 327 and 283 frequent times respectively (Fig. 2).

- Inbound flights SV1696 and SV1672 have the most demand to connect passengers from AHB to MNL destination with 667 and 632 frequent times respectively (Fig. 3).

- Figures 4, 5, and 6 show that Thursday, Wednesday, and Friday are the most demanded days of the week for connecting passengers to travel from AHB to DAC, AHB to ISB, and AHB to MNL respectively.

- Figures 7, 8, and 9 show that September, January, and March are the most demanded months of the year for connecting passengers to travel from AHB to DAC, AHB to ISB, and AHB to MNL respectively.

\subsection{The Results Obtained from Multiple Regression and ARIMA Forecasting Models}

The multiple regression and ARIMA models were applied for the data of DAC, ISB, and MNL outbound flights. The connecting passengers were independent variables in the regression model while the inbound flights, weekdays, and connecting times were dependent variables. The regression model gives the significance of variability and the ARIMA model gives the future forecasting of connecting passengers that helps to recommend operating plan to improve domestic connectivity at SAUDIA. 
Table 2. Sample data for connecting passengers from ABH to DAC.

\begin{tabular}{|c|c|c|c|c|c|c|c|c|c|}
\hline Inbound Flight & Date & MONTH & LF & DOW & Inbound Leg & Outbound Flight & Outbound Leg & $\begin{array}{l}\text { Connecting } \\
\text { passengers }\end{array}$ & $\begin{array}{c}\text { Connection } \\
\text { Time }\end{array}$ \\
\hline SV 1620 & 1-Jan-14 & Jan & $94 \%$ & Wed & AHB-RUH & SV 808 & RUH-DAC & 10 & $2: 35$ \\
\hline SV 1672 & 2-Jan-14 & Jan & $95 \%$ & Thu & AHB-RUH & SV 808 & RUH-DAC & 4 & $4: 55$ \\
\hline SV 1620 & 2-Jan-14 & Jan & $89 \%$ & Thu & AHB-RUH & SV 808 & RUH-DAC & 7 & $2: 55$ \\
\hline SV 1696 & 2-Jan-14 & Jan & $98 \%$ & Thu & AHB-RUH & SV 808 & RUH-DAC & 1 & $6: 55$ \\
\hline SV 1672 & 2-Jan-14 & Jan & $95 \%$ & Thu & AHB-RUH & SV 800 & RUH-DAC & 1 & $7: 55$ \\
\hline SV 1620 & 3-Jan-14 & Jan & $93 \%$ & Fri & AHB-RUH & SV 800 & RUH-DAC & 3 & $5: 55$ \\
\hline SV 1696 & 3-Jan-14 & Jan & $95 \%$ & Fri & AHB-RUH & SV 808 & RUH-DAC & 23 & $3: 38$ \\
\hline SV 1620 & 3-Jan-14 & Jan & $93 \%$ & Fri & AHB-RUH & SV 808 & RUH-DAC & 6 & $2: 55$ \\
\hline SV 1864 & 3-Jan-14 & Jan & $100 \%$ & Fri & AHB-RUH & SV 808 & RUH-DAC & 1 & $9: 35$ \\
\hline SV 1958 & 4-Jan-14 & Jan & $83 \%$ & Sat & AHB-RUH & SV 800 & RUH-DAC & 1 & $1: 40$ \\
\hline SV 1672 & 4-Jan-14 & Jan & $100 \%$ & Sat & AHB-RUH & SV 808 & RUH-DAC & 2 & $4: 35$ \\
\hline SV 1868 & 4-Jan-14 & Jan & $100 \%$ & Sat & AHB-RUH & SV 808 & RUH-DAC & 5 & $1: 55$ \\
\hline SV 1620 & 5-Jan-14 & Jan & $98 \%$ & Sun & AHB-RUH & SV 808 & RUH-DAC & 4 & $2: 35$ \\
\hline SV 1696 & 6-Jan-14 & Jan & $98 \%$ & Mon & AHB-RUH & SV 808 & RUH-DAC & 2 & $6: 35$ \\
\hline SV 1672 & 6-Jan-14 & Jan & $95 \%$ & Mon & AHB-RUH & SV 808 & RUH-DAC & 10 & $2: 00$ \\
\hline SV 1620 & 7-Jan-14 & Jan & $98 \%$ & Tue & AHB-RUH & SV 808 & RUH-DAC & 2 & $2: 35$ \\
\hline SV 1672 & 7-Jan-14 & Jan & $95 \%$ & Tue & AHB-RUH & SV 808 & RUH-DAC & 1 & $4: 35$ \\
\hline SV 1662 & 7-Jan-14 & Jan & $91 \%$ & Tue & AHB-RUH & SV 3814 & RUH-DAC & 9 & $2: 35$ \\
\hline SV 1620 & 8-Jan-14 & Jan & $98 \%$ & Wed & AHB-RUH & SV 808 & RUH-DAC & 1 & $3: 15$ \\
\hline SV 1868 & 8-Jan-14 & Jan & $100 \%$ & Wed & AHB-RUH & SV 808 & RUH-DAC & 11 & $2: 35$ \\
\hline SV 1680 & 8-Jan-14 & Jan & $92 \%$ & Wed & AHB-RUH & SV 800 & RUH-DAC & 5 & $3: 25$ \\
\hline SV 1678 & 9-Jan-14 & Jan & $78 \%$ & Thu & AHB-RUH & SV 800 & RUH-DAC & 4 & $2: 35$ \\
\hline SV 1620 & 9-Jan-14 & Jan & $96 \%$ & Thu & AHB-RUH & SV 808 & RUH-DAC & 19 & $3: 15$ \\
\hline SV 1672 & 9-Jan-14 & Jan & $96 \%$ & Thu & AHB-RUH & SV 808 & RUH-DAC & 4 & $5: 15$ \\
\hline
\end{tabular}

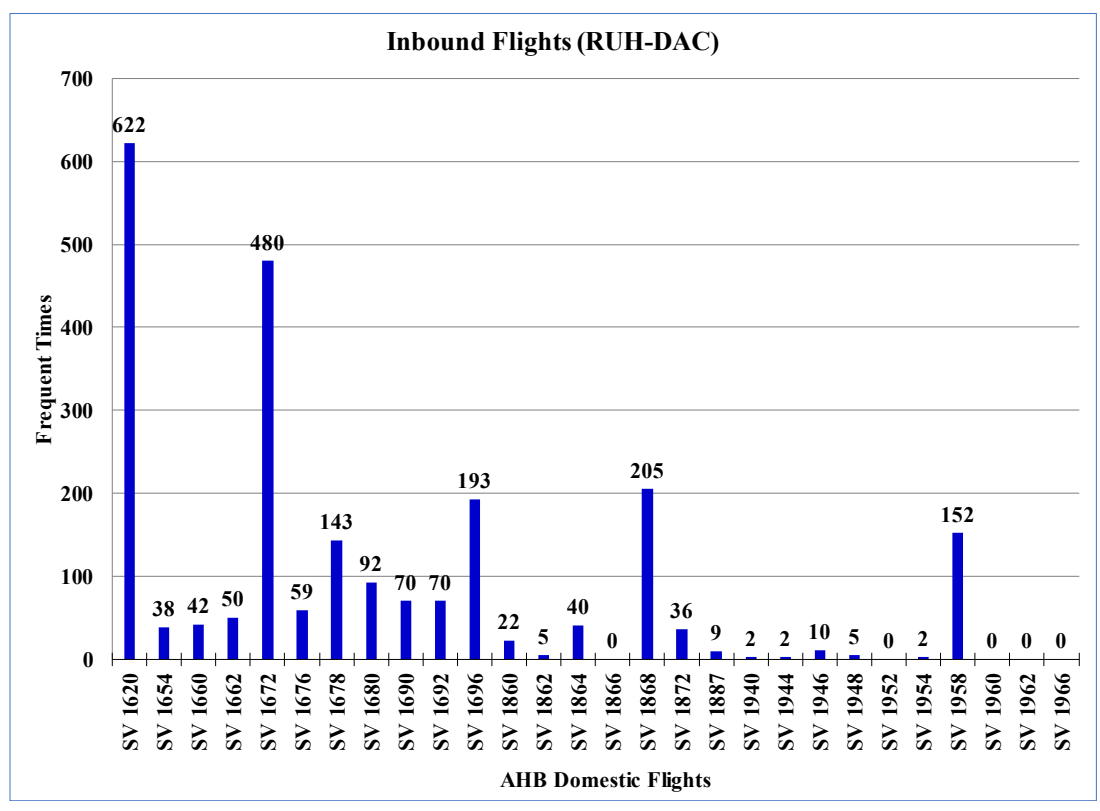

Fig. 1. Demanded AHB flights to DAC. 


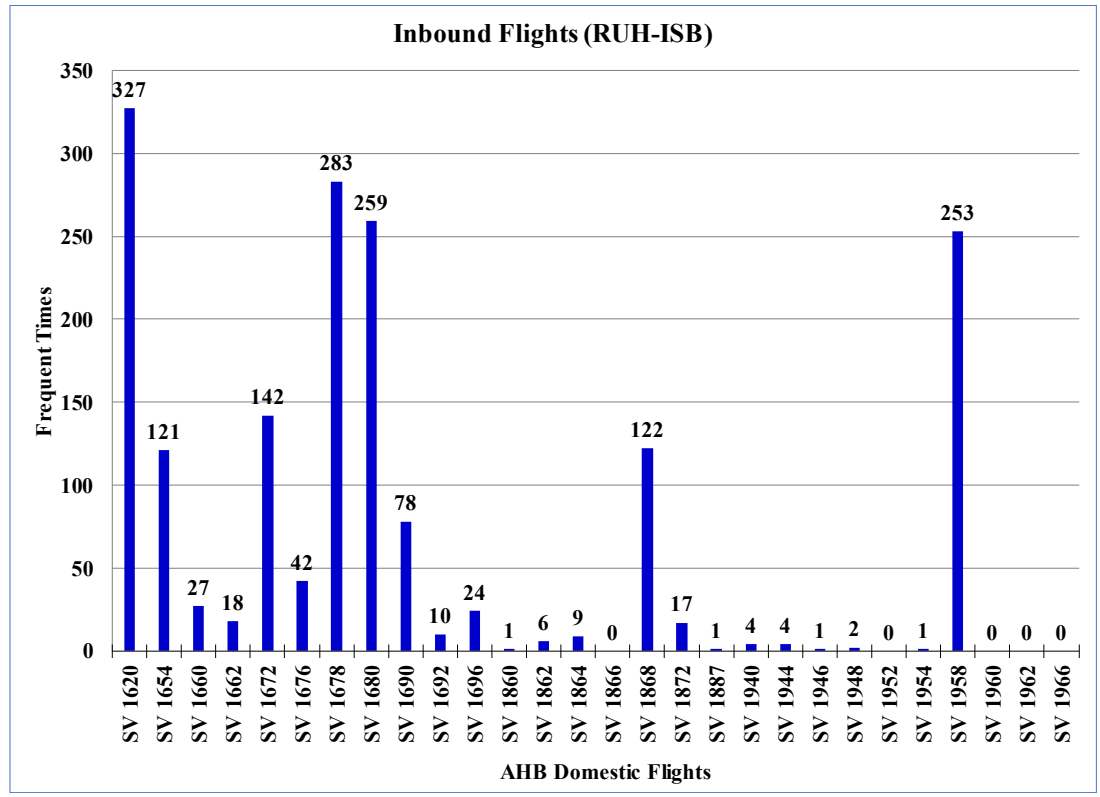

Fig. 2. Demanded AHB flights to ISB.

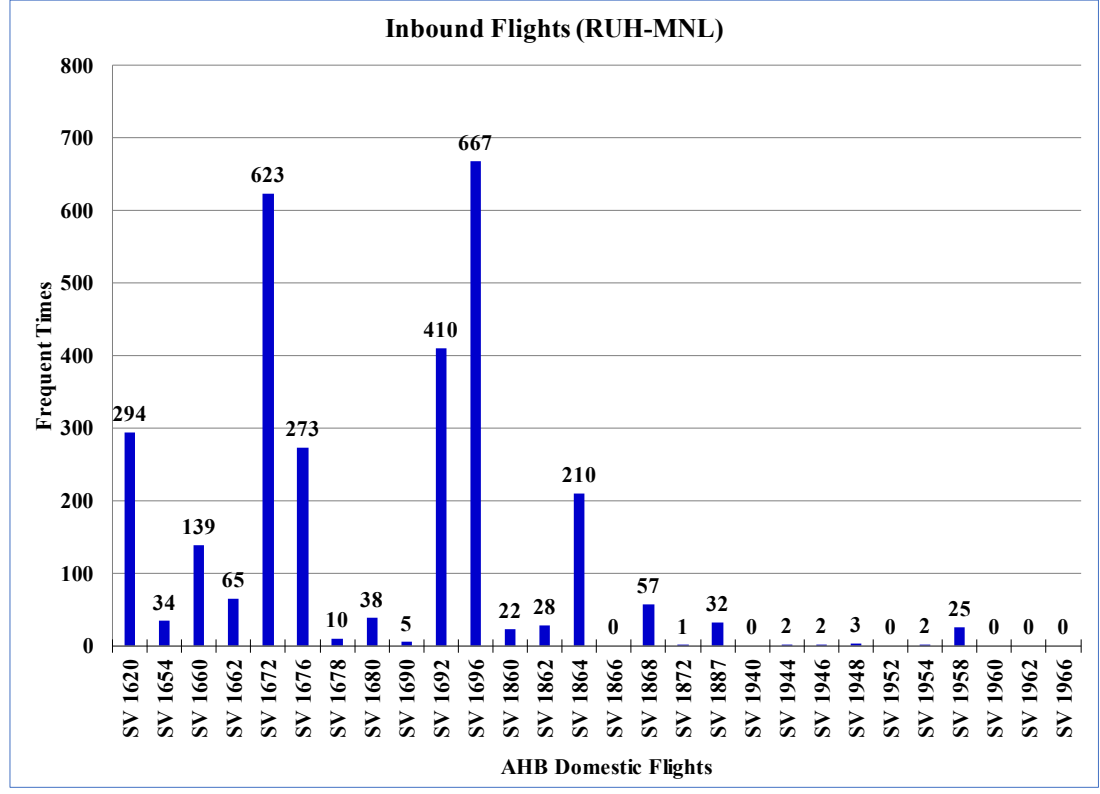

Fig. 3. Demanded AHB flights to MNL. 


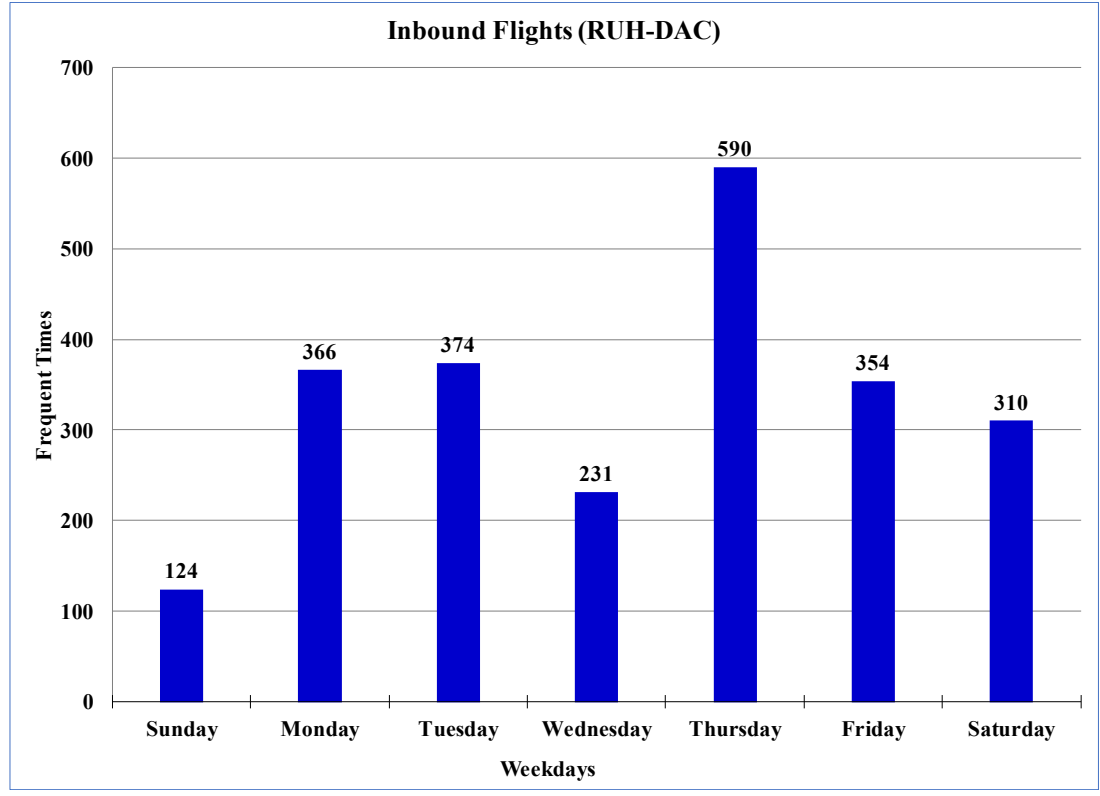

Fig. 4. Demanded weekdays for AHB flights to DAC.

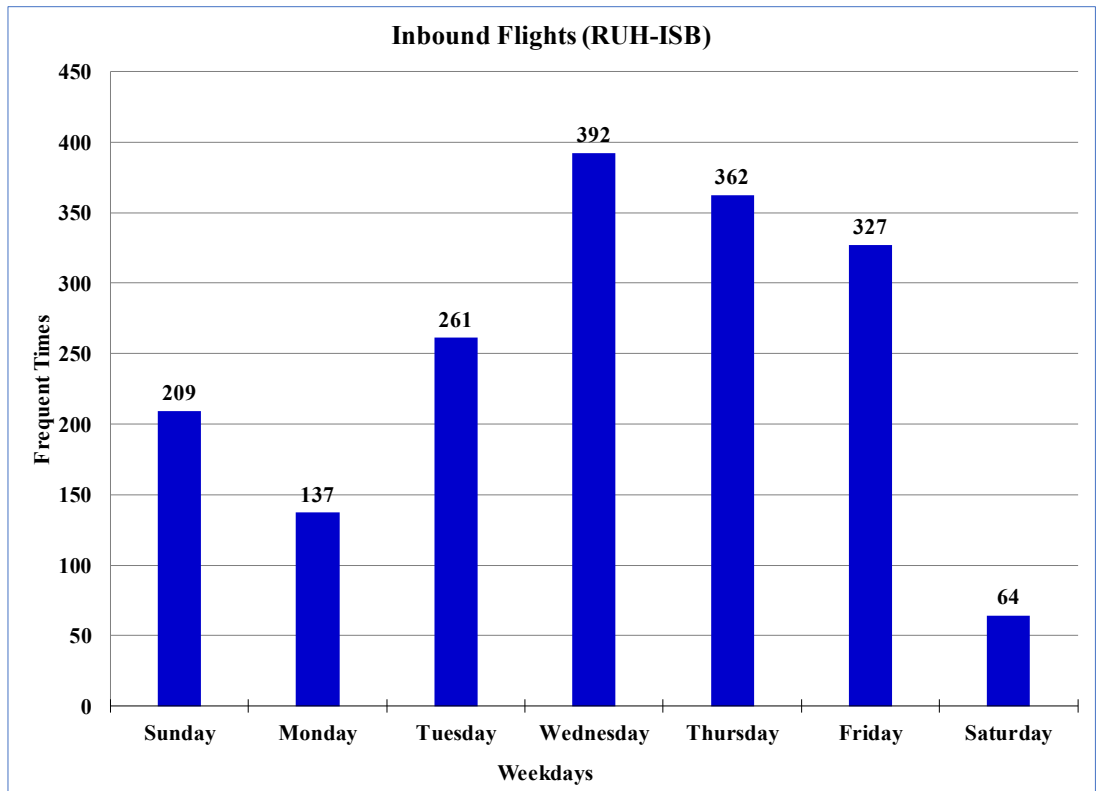

Fig. 5. Demanded weekdays for AHB flights to ISB. 


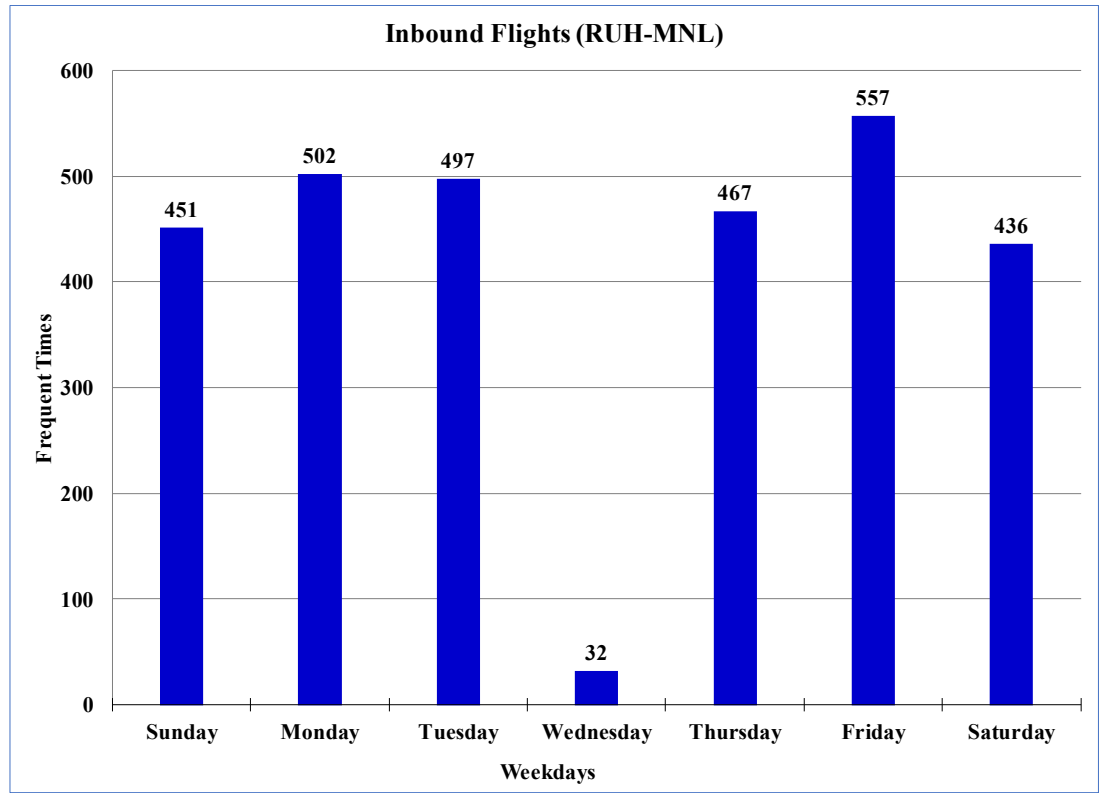

Fig. 6. Demanded weekdays for AHB flights to MNL.

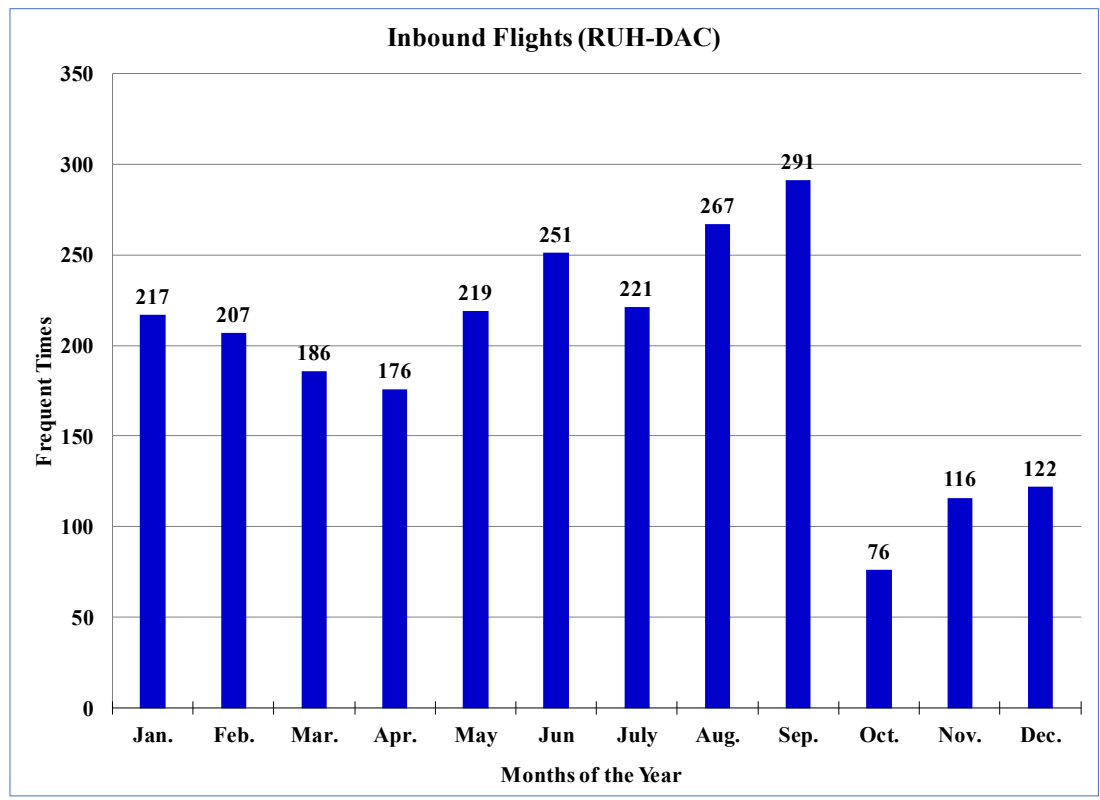

Fig. 7. Demanded months for AHB flights to DAC. 


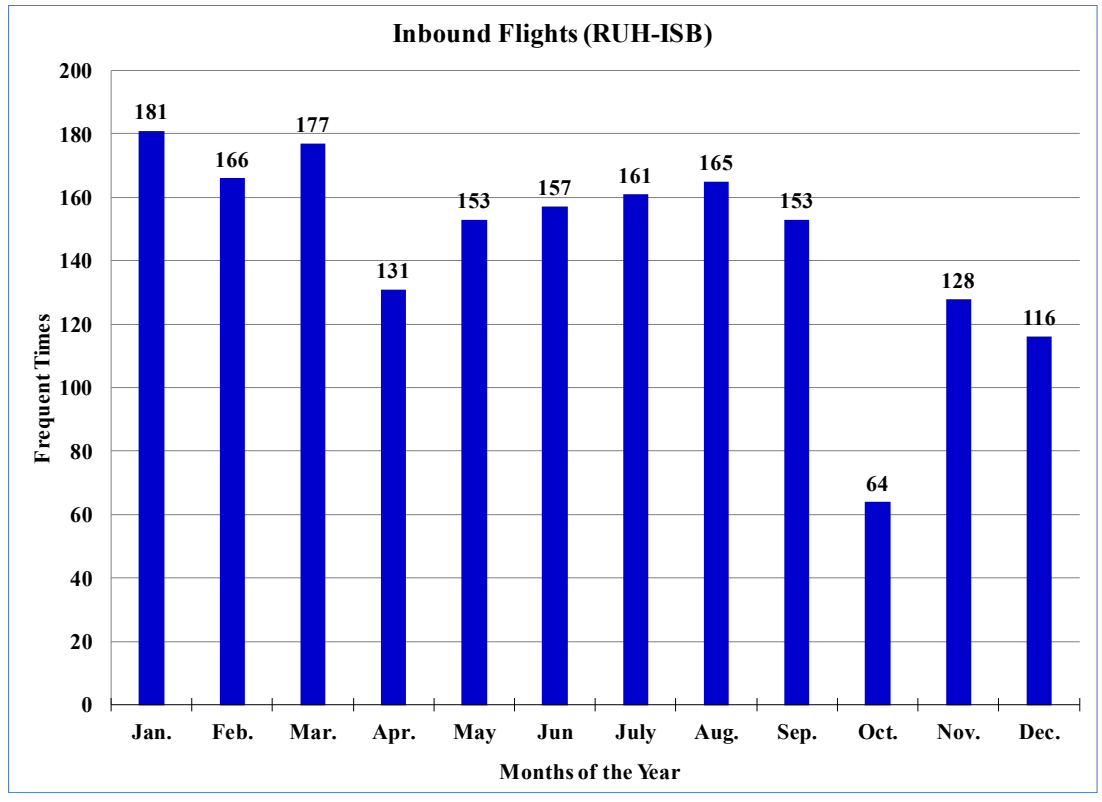

Fig. 8. Demanded months for AHB flights to ISB.

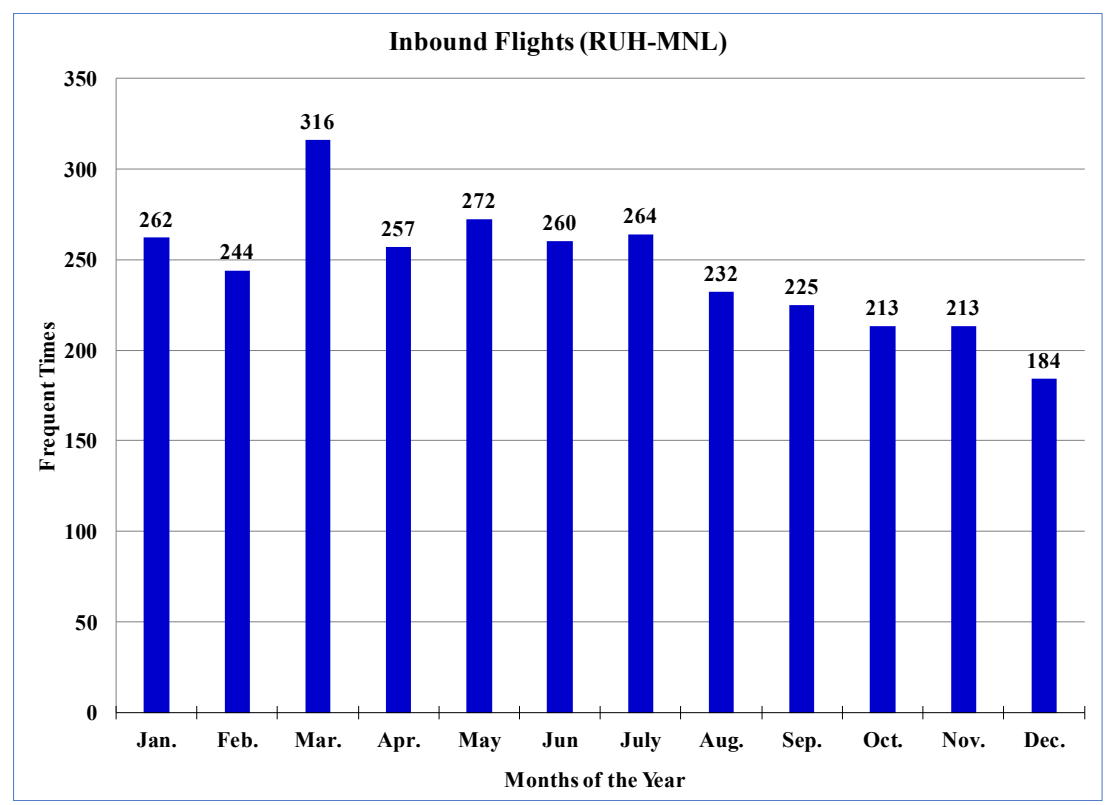

Fig. 9. Demanded months for AHB flights to MNL.

\subsubsection{The Results Obtained for DAC Outbound Flights}

- The significance factors for the inbound flights, weekdays, and connection times in hours are $0.62,0.01$, and 0.36 respectively. This means that the most affecting factor on the connecting passengers is inbound flights followed by connection times and finally weekdays.

- Figure 7 shows that June, August and September had the most frequent times to travel to DAC with values 251, 267, and 291 
respectively. From the data collected it is shown that the number of connecting passengers over these three months were 388,318 , and 611 in the year 2014 besides 485, 471, and 568 in the year 2015, and 539, 790, and 373 in the year 2016 . On the other hand, as given in Table 3, the maximum forecasted number of connecting passengers for June, August, and September of the year 2017 are 545, 567, and 546 respectively. As a result, from the data collected and the forecasted values, the expected increases for connecting passengers demand, to travel from AHB to DAC via RUH will be $16 \%, 7 \%$, and $6 \%$ in June, August, and September, respectively, of the year 2017.

\subsubsection{The Results Obtained for ISB Outbound Flights}

- The significance factors for the inbound flights, weekdays, and connection times in hours are $0.41,0.23$, and 0.36 respectively. This means that the most affecting factor on the connecting passengers is inbound flights followed by connection times and finally weekdays.

- Figure 8 shows that January, February and March had the most frequent times to travel to ISB with values 181,166 , and 177 respectively. From the data collected it is shown that the number of connecting passengers over these three months were 363 , 284, and 194 in the year 2014 besides 452, 333 , and 265 in the year 2015, and 186, 236, and 294 in the year 2016. On the other hand, as given in Table (4), the maximum forecasted number of connecting passengers for June, August, and September of the year 2017 are 489,442 , and 490 respectively. As a result, from the data collected and the forecasted values, the expected increases for connecting passengers demand, to travel from AHB to ISB via RUH will be $46 \%, 55 \%$, and $95 \%$ in June, August, and September, respectively, of the year 2017.

\subsubsection{The Results Obtained for MNL Outbound Flights}

- The significance factors for the inbound flights, weekdays, and connection times in hours are 0.03, 0.01, and 0.96 respectively. This means that the most affecting factor on the connecting passengers is inbound flights followed by connection times and finally weekdays.

- Figure 9 shows that March, May and July had the most frequent times to travel to MNL with values 316, 272, and 264 respectively. From the data collected it is shown that the number of connecting passengers over these three months were 333, 379, and 262 in the year 2014 besides 478, 456, and 411 in the year 2015, and 481, 460, and 262 in the year 2016. On the other hand, as given in Table 5, the maximum forecasted number of connecting passengers for June, August, and September of the year 2017 are 450,477 , and 454 respectively. As a result, from the data collected and data forecasted, the expected increases for connecting passengers demand, to travel from AHB to MNL via RUH will be $4 \%, 11 \%$, and $46 \%$ in June, August, and September, respectively, of the year 2017.

\section{Recommendations for SAUDIA}

\section{Operational Strategy}

This paper handled the problem of the passengers who had connection for international flights between Riyadh (RUH) and 14 international destinations, and they are looking for seats in SAUDIA domestic flights between Abha (AHB) and RUH to continue their international flights. A forecasting model was developed for three international stations that had high demand, namely Dhaka (DAC), Islamabad (ISB), and Manila (MNL), to determine the expected demand on domestic flights with a recommendation on the types of 
airplanes and their capacity to fulfill this demand in order to maximize the total revenue of Saudi airplanes comparing the competitors' airplanes. The results obtained from the proposed forecasting models led to the following recommendations to improve domestic to international connectivity.

Table 3. Forecasting generation for DAC.

\begin{tabular}{|c|c|c|c|c|c|c|}
\hline Month & Year & DAC Destination & $\begin{array}{c}\text { Number of } \\
\text { Connecting } \\
\text { Passenginers }\end{array}$ & Mean & $\begin{array}{l}\text { Std. } \\
\text { Error }\end{array}$ & $\begin{array}{c}\text { Std. } \\
\text { Deviation }\end{array}$ \\
\hline \multirow{2}{*}{ June } & \multirow{6}{*}{2017} & $\begin{array}{l}\text { LCL predicted value from connecting } \\
\text { passengers - ARIMA }(10,1,1)\end{array}$ & 177 & 5.910 & 0.001 & 0.003 \\
\hline & & $\begin{array}{l}\text { UCL predicated value from connecting } \\
\text { passengers - ARIMA }(10,1,1)\end{array}$ & 545 & 18.180 & 0.001 & 0.003 \\
\hline \multirow{2}{*}{ August } & & $\begin{array}{l}\text { LCL predicted value from connecting } \\
\text { passengers - ARIMA }(10,1,1)\end{array}$ & 184 & 5.930 & 0.001 & 0.003 \\
\hline & & $\begin{array}{l}\text { UCL predicated value from connecting } \\
\text { passengers - ARIMA }(10,1,1)\end{array}$ & 564 & 18.190 & 0.001 & 0.004 \\
\hline \multirow{2}{*}{ September } & & $\begin{array}{l}\text { LCL predicted value from connecting } \\
\text { passengers - ARIMA }(10,1,1)\end{array}$ & 178 & 5.940 & 0.001 & 0.003 \\
\hline & & $\begin{array}{l}\text { UCL predicated value from connecting } \\
\text { passengers - ARIMA }(10,1,1)\end{array}$ & 546 & 18.200 & 0.001 & 0.004 \\
\hline
\end{tabular}

LCL : Lower Control Limit

UCL: Upper Control Limit

Table 4. Forecasting generation for ISB.

\begin{tabular}{|c|c|l|c|c|c|c|}
\hline \multirow{2}{*}{ Month } & \multirow{2}{*}{ Year } & \multicolumn{1}{|c|}{ ISB Destination } & $\begin{array}{c}\text { Number of } \\
\text { Connecting } \\
\text { Passenginers }\end{array}$ & Mean & $\begin{array}{c}\text { Std. } \\
\text { Error }\end{array}$ & $\begin{array}{c}\text { Std. } \\
\text { Deviation }\end{array}$ \\
\hline \multirow{2}{*}{ February } & \multirow{2}{*}{2017} & 164 & 5.282 & 0.0009 & 0.0050 \\
\hline & $\begin{array}{l}\text { LCL predicted value from connecting } \\
\text { passengers - ARIMA (14, 1, 1) }\end{array}$ & $\begin{array}{l}\text { UCL predicated value from connecting } \\
\text { passengers - ARIMA (14,1,1) }\end{array}$ & 489 & 15.766 & 0.0010 & 0.0053 \\
\cline { 3 - 7 } & $\begin{array}{l}\text { LCL predicted value from connecting } \\
\text { passengers - ARIMA (14, 1, 1) }\end{array}$ & 148 & 5.297 & 0.0008 & 0.0043 \\
\hline & $\begin{array}{l}\text { UCL predicated value from connecting } \\
\text { passengers - ARIMA (14,1,1) }\end{array}$ & 442 & 15.783 & 0.0009 & 0.0046 \\
\cline { 3 - 7 } & $\begin{array}{l}\text { LCL predicted value from connecting } \\
\text { passengers - ARIMA (14, 1, 1) }\end{array}$ & 165 & 5.313 & 0.0009 & 0.0050 \\
\hline & $\begin{array}{l}\text { UCL predicated value from connecting } \\
\text { passengers - ARIMA (14,1,1) }\end{array}$ & 490 & 16.799 & 0.0010 & 0.0053 \\
\hline
\end{tabular}

LCL : Lower Control Limit

UCL: Upper Control Limit

Table 5. Forecasting generation for MNL.

\begin{tabular}{|c|c|c|c|c|c|c|}
\hline Month & Year & MNL Destination & $\begin{array}{c}\text { Number of } \\
\text { Connecting } \\
\text { Passenginers }\end{array}$ & Mean & $\begin{array}{l}\text { Std. } \\
\text { Error }\end{array}$ & $\begin{array}{c}\text { Std. } \\
\text { Deviation }\end{array}$ \\
\hline \multirow{2}{*}{ March } & \multirow{6}{*}{2017} & $\begin{array}{l}\text { LCL predicted value from connecting } \\
\text { passengers - ARIMA }(10,1,1)\end{array}$ & 168 & 5.43 & 0.002 & 0.009 \\
\hline & & $\begin{array}{l}\text { UCL predicated value from connecting } \\
\text { passengers - ARIMA }(10,1,1)\end{array}$ & 450 & 14.52 & 0.002 & 0.009 \\
\hline \multirow{2}{*}{ May } & & $\begin{array}{l}\text { LCL predicted value from connecting } \\
\text { passengers - ARIMA }(10,1,1)\end{array}$ & 182 & 5.87 & 0.002 & 0.010 \\
\hline & & $\begin{array}{l}\text { UCL predicated value from connecting } \\
\text { passengers - ARIMA }(10,1,1)\end{array}$ & 477 & 15.38 & 0.002 & 0.010 \\
\hline \multirow{2}{*}{ July } & & $\begin{array}{l}\text { LCL predicted value from connecting } \\
\text { passengers - ARIMA }(10,1,1) \\
\end{array}$ & 172 & 5.56 & 0.002 & 0.010 \\
\hline & & $\begin{array}{l}\text { UCL predicated value from connecting } \\
\text { passengers - ARIMA }(10,1,1)\end{array}$ & 454 & 14.65 & 0.002 & 0.010 \\
\hline
\end{tabular}

LCL : Lower Control Limit

UCL: Upper Control Limit 


\subsection{Recommendations for Domestic Flight AHB-RUH Connected to International Flight DAC}

The Current aircraft type is A320 with seat configuration $12 \mathrm{~J} / 120 \mathrm{Y}$. During months of June, August, and September of the year 2017, the model predicted an increase in connecting passengers by $16 \% ; 7 \%$ and $6 \%$ respectively. So, the following operating strategy, for network and scheduling planning, is recommended to keep international connecting passengers:

- Set direct flights from AHB to DAC with an aircraft type A321 having seat configuration $20 \mathrm{~J} / 145 \mathrm{Y}$ especially on Thursdays weekly from each month.

- Upgrade flights SV1620 and SV1672 with an aircraft type A321 having seat configuration 20J/145Y for Monday, Tuesday, Friday and Saturday of each week of each month.

- If upgrade is not possible, protect $30 \%$ of seats in the flight's current capacity for international connecting passengers.

- Apply 2 hours' connection time between connection flights that is most desire for passengers.

\subsection{Recommendations for Domestic Flight AHB-RUH Connected to International Flight ISB}

The Current aircraft type is A320 with seat configuration $12 \mathrm{~J} / 120 \mathrm{Y}$. During months of January, August, and September of the year 2017, the model predicted an increase in connecting passengers by $46 \% ; 55 \%$ and $95 \%$ respectively. So, the following operating strategy, for network and scheduling planning, is recommended to keep international connecting passengers:

- Set one direct flight from AHB to ISB with an aircraft type A333 having seat configuration of $36 \mathrm{~J} / 262 \mathrm{Y}$ on Wednesday and Friday weekly from each month to cover an increase in expected demand.

- Upgrade flights SV1620; SV1678; SV1680 and SV1958 with an aircraft type of A333 having seat configuration of $36 \mathrm{~J} / 262 \mathrm{Y}$ for Wednesday, Thursday, and Friday weekly from each month.

- If upgrade is not possible, protect $30 \%$ of seats in flight current capacity for international connection passengers.

- Apply 2 hours' connection time between connection flights that is most desire for passengers.

\subsection{Recommendations for Domestic Flight AHB-RUH Connected to International Flight MNL}

The Current aircraft type is A320 with seat configuration $12 \mathrm{~J} / 120 \mathrm{Y}$. During months of March, May, July of the year 2017, the model predicted an increase in connecting passengers by $4 \% ; 11 \% ; 46 \%$ and $20 \%$ respectively. So, the following operating strategy, for network and scheduling planning, is recommended to keep international connecting passengers:

- Set one direct flight from AHB to MNL with an aircraft type of A333 having seat configuration of $36 \mathrm{~J} / 262 \mathrm{Y}$ on Friday weekly during from each month to cover an increase of the expected demand for connecting passengers.

-Upgrade flights SV1672, SV1692 and SV1696 with an aircraft type of A321, having seat configuration of $20 \mathrm{~J} / 145 \mathrm{Y}$ for Monday and Saturday weekly from each month.

- If upgrade is not possible, protect $30 \%$ of seats in flight current capacity for international connecting passengers. 
- Apply 2 hours' connection time between connection flights that is most desire for passengers.

\subsection{Recommendation for any Future Studies}

The proposed forecasting model can be extended to involve the financial issues such as operational costs and ticket pricing as a dependent variable to the connecting passengers' demand. This extended study may change the operations strategy of Saudi Arabian Airlines compared to what recommended here or may support the current recommendations.

\section{References}

[1] CSR Saudi Arabia 2014-2015 Sponsors, Retrieved April Jan 14, 2016, from http://www.csrsummitsaudi.com/2014/Site-Root/ Sponsorship/Sponsors/

[2] Abdullah O., Seraj Y. and Sajjad M., "The determinants of domestic air travel demand in the kingdom of Saudi Arabia", Journal of Air Transportation Worldwide, 5(2): 72-86 (2000).

[3] Katsuya K., Delaurentis, D. A. and Aaron, S., "Development of Network Restructuring Models for Improved Air Traffic Forecasts", Transportation Research Part C: Emerging Technologies, 18(6): 937949 (2010).

[4] Aderamo, A. J., "Demand for Air Transport in Nigeria", Journal of Economics, 1(1): 23-3 (2010).

[5] Fahad, A. and Nayef, A., "Forecasting Air travel demand in Kuwait", Journal of Engineering Research, 1(1): 113-143 (2013).

[6] Orhan S., "Demand Forecasting For Domestic Air Transportation In Turkey", The Open Transportation Journal, 7(1): 20-26 (2013).

[7] Chi-Ok, O. and Bernard J., "Evaluating Time-Series Models to Forecast the Demand for Tourism in
Singapore: Comparing Within-Sample and Post Sample Results", Journal of Travel Research, 43(4): 404-413 (2005).

[8] Christine, L. and Michael, M., "Forecasting tourist arrivals", Annals of Tourism Research, 28(4): 965-977 (2001).

[9] Alberto, A. and Maria, N., "A multivariate ARIMA model to forecast air transport demand", Proceedings of the Association for European Transport and Contributors, 1-14 (2006).

[10] John, C., "Time series analyses of UK outbound travel by air", Journal of Travel research, 44(3): 335-347 (2006).

[11] Emir, E. and Gabriel, R., "Evaluating Time Series Models in Short and Long-Term Forecasting of Canadian Air Passenger Data", Department of Economics, University of Ottawa, (2003). Retrieved Feb 10, 2016, from https://ideas.repec.org/p/ott/wpaper/0306e.html

[12] Ching-Fu, C., Yu-Hern, C. and Yu-Wei, C., "Seasonal ARIMA forecasting of inbound air travel arrivals to Taiwan", Transportmetrica, 5(2): 125-140, (2009).

[13] Mukesh, K. and Somesh, M., "Passenger Demand Forecasting of Indian Aviation Industry", Annual International Conference of the Society of Operations Management, Proceedings of SOM 2014, 532-537 (2014).

[14] John, C., "Time Series Analyses of UK Outbound Travel by Air", Journal of Travel Research, 44(3): 335347 (2006).

[15] Murat Ç., "Building proper forecast model for daily air passenger demand", International Antalya hospitality tourism and travel research (2014), Retrieved Feb. 10, 2016, from https://www.researchgate.net/publication/280557143_B uilding_Proper_Forecast_Model_for_Daily_Air_Passen ger_Demand_A_Study_of_Antalya_International_Airp ort

[16] Guoqiang, P., "Time series forecasting using a hybrid ARIMA and neural network model", Neurocomputing, 50: $159-175,(2003)$.

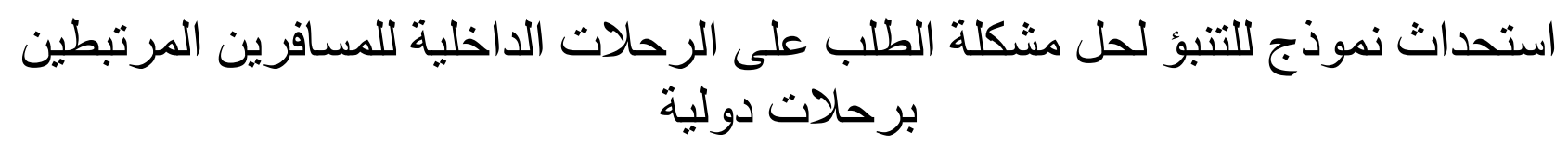




\section{رياض الحسن، و رضا عبد العال، و حميد السلمى

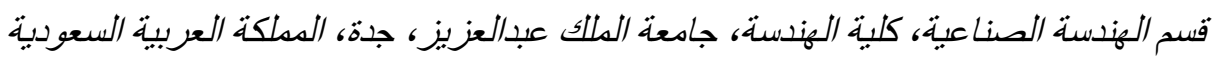 engr.riyadhali@gmail.com}

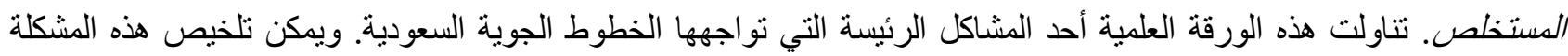

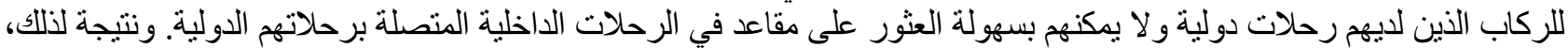

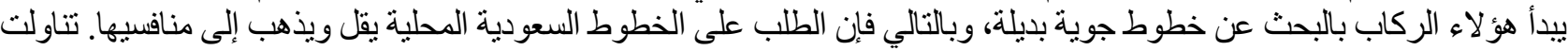

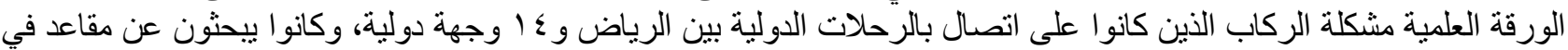

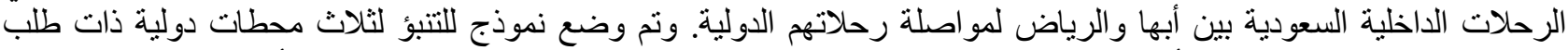

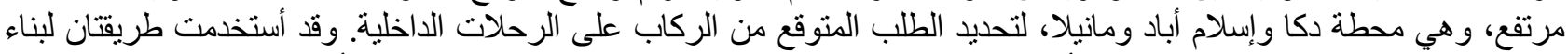

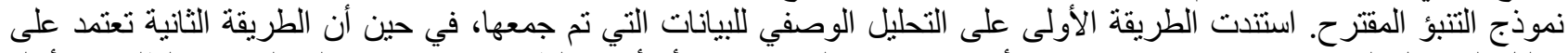

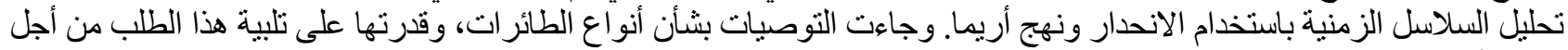
تحقيق أقصى قرر من الإير ادات الإجمالية للطائر ات السعودية مقارنة مع طائر ات التان المنافسين.

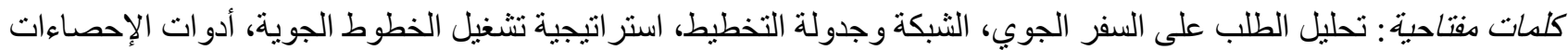

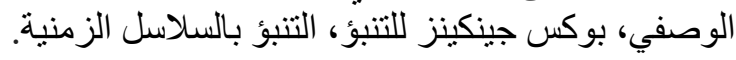

